\title{
Facilities for carers of in-patients in forensic psychiatric services in England and Wales
}

\author{
Irene Cormac, ${ }^{1}$ Drew Lindon, ${ }^{2}$ Hannah Jones, ${ }^{3}$ Trevor Gedeon, ${ }^{4}$ Michael Ferriter ${ }^{3}$
}

The Psychiatrist (2010), 34, 381-384, doi: 10.1192/pb.bp.109.025833

${ }^{1}$ Rampton Hospital, Retford,

Nottinghamshire; ${ }^{2}$ The Princess Royal

Trust for Carers, Woodford Green,

Essex; ${ }^{3}$ Institute of Mental Health,

Clair Chilvers Centre, Rampton

Hospital; ${ }^{4}$ Hull Royal Infirmary

Correspondence to Irene Cormac

(irene.cormac@nottshc.nhs.uk)

\begin{abstract}
Aims and method A postal survey of forensic psychiatric facilities in England and Wales was undertaken to obtain information about the services provided for carers of in-patients within these services.
\end{abstract}

Results Forensic psychiatric services vary in the support and facilities provided for carers. Many do not comply with current legislation for carers. Most units informed carers of their rights to have an assessment, but only a minority provided facilities for carers from Black and minority ethnic backgrounds.

\begin{abstract}
Clinical implications Forensic psychiatric services should meet standards for the involvement and support of carers in mental health settings, and comply with legislation for carers.
\end{abstract}

Declaration of interest I.C. was a member of the Partners in Care campaign of the Royal College of Psychiatrists and the Princess Royal Trust for Carers. D.L. is employed by the Princess Royal Trust for Carers.
The Princess Royal Trust for Carers defines a carer as someone of any age who provides unpaid support to family or friends who could not manage without this help. This could be caring for a relative, partner or friend who is ill, frail, disabled or has mental health or substance use problems (www.carers.org/who-is-a-carer,118,GP.html). The government in England and Wales has acknowledged the essential role of carers as 'partners in care', as well as their entitlement to assessment and support, in its national carers' strategy. ${ }^{1}$

The right for carers to have a carers' assessment was enshrined in the Carers and Disabled Children's Act 2000 and later extended by the Carers (Equal Opportunities) Act 2004, to include:

1 the right for carers to be offered an assessment, rather than having to ask for it, and

2 the right for carers to have their aspirations for work and leisure to be taken into account.

In addition, the Community Care (Delayed Discharges etc.) Act 2003 gives carers the right to be consulted about discharge of their care recipient from hospital and for carers to have an assessment in their own right.

During the Partners in Care campaign by the Royal College of Psychiatrists and the Princess Royal Trust for Carers (2004-2005), a leaflet was produced to advise and inform carers of patients in forensic psychiatric services. ${ }^{2}$ Following the Partners in Care campaign, the Forensic Psychiatry Faculty of the College and the Princess Royal Trust for Carers wanted a survey to be undertaken to assess the facilities and arrangements for carers of in-patients in forensic psychiatric units in England and Wales.

This brief report describes the result of this survey and also includes a set of standards subsequently commissioned by the College Research and Training Unit and produced by two of the authors (I.C. and D.L.).

\section{Method}

In 2008 , we carried out a postal survey of medium and low secure forensic psychiatric services in England and Wales. We identified the units from a directory of forensic psychiatric services, ${ }^{3}$ updated with additional information from lists compiled in Rampton Hospital. Senior nurse managers were invited to complete a questionnaire and return it in a stamped addressed envelope, marked with a unique number. A second questionnaire was sent to non-responders.

The questionnaire topics were chosen from a selection of items in the leaflet on forensic psychiatric services for carers $^{2}$ and from discussions with experts in the field. We asked which professional group was responsible for identifying carers, as well as about the availability of support for carers of in-patients, the availability of suitable facilities, and visiting arrangements for families and children. We also asked whether carers were informed about their rights to an assessment of needs and the provision of services for relatives of Black and minority ethnic patients. 


\begin{tabular}{|c|c|c|c|c|c|}
\hline Question & $n$ & $\%$ & Question & $n$ & $\%$ \\
\hline \multicolumn{3}{|l|}{ Who is responsible for identifying carers? ${ }^{a}$} & \multicolumn{3}{|l|}{ Is there a list of local accommodation } \\
\hline Medical records & 10 & 14.7 & available? & & \\
\hline Key worker/named nurse & 39 & 57.4 & Yes & 34 & 50.0 \\
\hline Carer support service & 0 & 0 & No & 27 & 39.7 \\
\hline Social worker & 48 & 70.6 & Did not answer & 7 & 10.3 \\
\hline Psychiatrist & 9 & 13.2 & \multirow{2}{*}{\multicolumn{3}{|c|}{$\begin{array}{l}\text { Does your service have an information pack for } \\
\text { carers? }\end{array}$}} \\
\hline No one in particular & 2 & 2.9 & & & \\
\hline \multicolumn{3}{|l|}{ How is first contact made? ${ }^{a}$} & Yes & 53 & 77.9 \\
\hline Letter & 43 & 63.2 & No & 10 & 14.7 \\
\hline Email & 2 & 2.9 & Did not answer & 5 & 7.4 \\
\hline Poster & 3 & 4.4 & \multicolumn{3}{|l|}{ Is your unit accessible by public transport? ${ }^{a}$} \\
\hline Telephone call & 51 & 75.0 & Railway station within 5 miles & 51 & 75.0 \\
\hline Leaflet & 4 & 5.9 & On bus route & 59 & 86.8 \\
\hline Personal visit & 15 & 22.1 & Only accessible by private transport or taxi & 5 & 7.4 \\
\hline \multicolumn{3}{|l|}{$\begin{array}{l}\text { Does your organisation have a service to provide } \\
\text { support for carers? }\end{array}$} & \multirow{2}{*}{\multicolumn{3}{|c|}{$\begin{array}{l}\text { Does your service have a carers' support } \\
\text { group? }\end{array}$}} \\
\hline $\begin{array}{l}\text { Yupport tor carers? } \\
\text { Yes }\end{array}$ & 43 & 63.2 & & & \\
\hline No & 25 & 36.8 & Yes & 19 & 27.9 \\
\hline \multirow{2}{*}{\multicolumn{3}{|c|}{ If no, do you have plans for a service for carers? }} & No & 47 & 69.1 \\
\hline & & 400 & Did not answer & 2 & 2.9 \\
\hline No & 15 & 60.0 & \multicolumn{3}{|l|}{ Is family therapy available for carers? } \\
\hline \multicolumn{3}{|l|}{ Do you employ carers' support workers? } & Yes & $\begin{array}{l}18 \\
23\end{array}$ & $\begin{array}{l}26.5 \\
338\end{array}$ \\
\hline Yes & 3 & 4.4 & $\begin{array}{l}\text { No } \\
\text { Don't know }\end{array}$ & $\begin{array}{r}23 \\
7\end{array}$ & $\begin{array}{l}33.8 \\
10.3\end{array}$ \\
\hline No & 58 & 85.3 & Did not answer & 20 & 29.4 \\
\hline Did not answer & 7 & 10.3 & \multirow{2}{*}{\multicolumn{3}{|c|}{$\begin{array}{l}\text { Does your service inform carers about their right } \\
\text { to have a carer's assessment at the point of } \\
\text { discharge? }\end{array}$}} \\
\hline \multicolumn{3}{|l|}{$\begin{array}{l}\text { If no, do you have plans to employ carers' support } \\
\text { workers? }\end{array}$} & & & \\
\hline Yes & 3 & 4.4 & Yes & 35 & 51.5 \\
\hline No & 52 & 76.5 & No & 5 & 7.4 \\
\hline Did not answer & 13 & 19.1 & Don't know & 8 & 11.8 \\
\hline \multirow{4}{*}{$\begin{array}{l}\text { Are any of the following facilities available } \\
\text { for carers in your organisation? } \\
\text { Visitor's room/private area } \\
\text { Family visiting room/area }\end{array}$} & & & Did not answer & 20 & 29.4 \\
\hline & & & \multirow{2}{*}{\multicolumn{3}{|c|}{$\begin{array}{l}\text { What proportion of your carers comes from } \\
\text { Black and minority ethnic groups? }\end{array}$}} \\
\hline & 54 & 79.4 & & & \\
\hline & 51 & 75.0 & $<10 \%$ & 42 & 61.8 \\
\hline \multicolumn{3}{|l|}{ Are there facilities and toys suitable for children? ${ }^{a}$} & $10-50 \%$ & 23 & 33.8 \\
\hline Pre-school & 43 & 63.2 & $>50 \%$ & 1 & 1.5 \\
\hline School-age & 34 & 50.0 & Did not answer & 2 & 2.9 \\
\hline Adolescent & 10 & 14.7 & \multirow{2}{*}{\multicolumn{3}{|c|}{$\begin{array}{l}\text { Do you have any special facilities for carers } \\
\text { of Black and minority ethnic groups? }\end{array}$}} \\
\hline \multirow{2}{*}{\multicolumn{3}{|c|}{$\begin{array}{l}\text { Is there accommodation for overnight stay, owned } \\
\text { by the service? }\end{array}$}} & & & \\
\hline & & & Yes & 7 & 10.3 \\
\hline Yes & 3 & 4.4 & No & 56 & 82.3 \\
\hline No & 65 & 95.6 & Did not answer & 5 & 7.4 \\
\hline
\end{tabular}

a. It was possible to indicate more than one response for these questions therefore the total percentage of responses is greater than $100 \%$.

\section{Results}

Questionnaires were sent to a total of 99 medium or low secure forensic psychiatric units; 68 units responded (68.7\%). The majority of replies $(n=41,60.3 \%)$ came from National Health Service units, 26 were from private units $(38.2 \%)$ and 1 from a charitable trust unit. Table 1 shows a summary of the results for each of the questions.

Social workers were responsible for identifying carers in $70.6 \%$ and nurses in $57.4 \%$ of the units. First contact with carers was most frequently made by telephone (75\%), followed by letter $(63.2 \%)$ and personal visit $(22.1 \%)$.

Services were provided to support carers in $63.2 \%$ of the units. Of the units which did not provide support for carers, $40 \%$ stated that they were planning to introduce such services. Three units $(4.4 \%)$ reported employing dedicated carer support workers.
Visitors' rooms or private areas were available in $79.4 \%$ and family visiting rooms in $75 \%$ of the units. Half the units (50\%) provided facilities and toys suitable for school-age children, $63.2 \%$ provided facilities and toys for pre-school children and $14.7 \%$ provided facilities for adolescents. All but one unit had a policy for child visitors. Visits by children required authorisation by the patient's clinical team in 66 units $(97.1 \%)$. In 50 units $(73.5 \%)$ staff with responsibility for facilitating visits by children and carers were required to have undertaken basic level child protection training.

Only $4.4 \%$ of the units provided accommodation for visitors, although half of the sample provided lists of local accommodation for carers.

Most of the units were accessible by public transport (92.6\%), with five units only accessible by private transport or taxi. 
Over a quarter of the units (27.9\%) had a carers' support group that was facilitated by staff. Similarly, just over a quarter $(26.5 \%)$ provided family therapy for carers and families.

Over half the units $(51.5 \%)$ reported that they informed carers of their rights to have a carer's assessment at the point of discharge.

The majority of units had less than $10 \%$ of carers from Black and minority ethnic groups. Although $35.3 \%$ reported having $10 \%$ or more of their carers from Black and minority ethnic groups, only $10.3 \%$ of units provided special facilities for such carers.

\section{Discussion}

The survey results highlight the important role that social workers and nursing staff have in the identification of carers. More than half of the forensic psychiatric services provided support for carers. It is encouraging that threequarters of units provided facilities for families and children to visit and similarly that child visits are checked and authorised by the clinical teams.

However, it is worrying that only just over a quarter of units provided support groups for carers. Carers are entitled, in law, to have a needs assessment, yet only just over a half of units informed carers of their rights to have a carer's assessment at the point of discharge.

We recognise that resources are needed to meet the requirements for carers to have an assessment in forensic, and indeed in all, psychiatric services. Undoubtedly, it is time-consuming to undertake a comprehensive carer's assessment with a carer, and it takes time to inform carers about services available to them and/or to arrange such services. In addition, it is expected that the carer's assessment will be reviewed annually. It is generally accepted as 'good practice' to offer a carer the opportunity to have their needs assessed by a staff member, other than the care recipient's psychiatrist or Care Programme Approach coordinator.

Ways to reduce the time taken for carers' assessments include giving the carer their assessment form to take away and consider for a few days before completing it, with assistance from staff if necessary. Local carers' services (either statutory or voluntary) may provide support or staff to assist carers with their assessments. However, many voluntary sector organisations would normally only agree to undertake these tasks under a service-level agreement with a local authority.

The beneficial effects of involving and supporting carers can offset the time spent undertaking carers' assessments. Support which meets a carer's own needs can enable them to provide better, and often more informed, support to the care recipient, whether the care recipient is a resident in forensic psychiatric services, in other psychiatric services or is living in the community. Support for carers can help foster greater independence and resilience, so they require less help in the longer term.

It is important to recognise that some carers do not wish to have a carer's assessment, or may only want specific issues to be addressed, without the need for a full assessment. More information and advice for staff undertaking carers' assessments is available from the Princess Royal Trust's website (www.carers.org/professionals/socialcare/carers-assessment,4377,PP.html).

The impact on workload and demand on resources could be a discrete and important topic for a future paper in its own right, especially if a cost-benefit analysis of carers' assessments is undertaken.

\section{Limitations}

We were unable to tell whether units from which we did not receive a reply to our survey provided any services for carers. In addition, the list of forensic services that we used may not have been complete. We did not survey the views of the carers themselves. We chose to send the questionnaire

Box 1 Standards for carers of in-patients in psychiatric settings

\section{Initial contact with carers}

Psychiatric services should routinely identify carers at the time of entry of a patient to the service. Carers should be given information about the service, including visiting arrangements, security arrangements, and facilities provided for carers and families during visits such as places to stay and transport availability.

\section{Carers' assessment}

A designated member of the clinical team should identify and arrange contact with carers, liaise with the clinical team, and assist with preparation of the patient's care plan, which may include contact with carers. Every carer should be offered an assessment of their needs, as required by the Carers (Equal Opportunities) Act 2004, National Service Framework for Mental Health (Standard 6) ${ }^{4}$ and the 2008 Care Programme Approach guidance. ${ }^{5}$

3. Information about a patient's mental health and progress It should be recorded that psychiatrists and/or other members of the clinical team have offered carers appropriate general information about mental health conditions and treatments, including medication and side-effects. When relevant, carers should be given information about the transition between the healthcare and criminal justice systems.

\section{Confidentiality}

Clinical teams should ask patients for their permission to share some, or all, of their health information with a named carer. There should be a record of what information the patient is willing to share with the carer, and under what circumstances this information is to be shared. Where appropriate, the attendance of carers at Care Programme Approach meetings should be encouraged and facilitated. Carers should also be involved in discharge or transfer processes, whenever possible.

\section{External support services}

Carers should be given a list of local services (including voluntary sector organisations) that provide support and information. Carers should be informed of suitable local support networks, carers' meetings and whether there are newsletters for carers.

\section{Facilities for visiting}

Suitable facilities must be provided for children and families to visit, in privacy and comfort. There must be procedures for safeguarding children and young persons during visiting of forensic psychiatric services. 
Box 2 Summary of services for carers in psychiatric settings

Contact with carers

- Initial contact with carers

- Offer carers a needs assessment

- Address issues about confidentiality and information sharing Providing information for carers

- When appropriate, about the patient's mental health and progress

- About voluntary sector organisations

- About carer's visits/accommodation

to senior nurse managers because of their overview of the services provided by their unit and we recognise that other professional groups could have provided different responses.

\section{Standards for carers of forensic in-patients}

This survey has identified several areas for improvement in services for carers in forensic psychiatric settings such as providing reliable methods of identification of carers, support and arrangements for visiting.

At the request of the Advisory Group for the Quality Network for Forensic Mental Health Services of the Royal College of Psychiatrists' Research and Training Unit, we (I.C. and D.L.) have prepared standards for carers of patients in forensic services, which have in part been informed by current legislation in England and Wales, and in part by the results of this survey (Boxes 1 and 2).

These standards address six key areas: initial contact with carers; carers' needs assessment; information for carers about the patient's mental health and progress; confidentiality and information sharing; information on voluntary sector organisations; and visiting facilities.

The standards can be used by forensic services and by regulators to measure best practice and to identify where improvements may be made in facilities and services for carers.

\section{Acknowledgements}

We thank Dr John O'Grady (former Chairman of the Forensic Faculty of the Royal College of Psychiatrists) for his support. We are grateful to staff from Rampton Hospital: Dr Emmet Larkin for his advice and Mrs Ann Thompson, Ms Andrina Clark and Ms Julie Smith for their assistance with data management.

\section{About the authors}

Irene Cormac, Consultant Forensic Psychiatrist, Rampton Hospital, Retford; Drew Lindon, Policy and Development Officer (Mental Health and Substance Misuse), the Princess Royal Trust for Carers; Hannah Jones, Research Assistant, Rampton Hospital; Trevor Gedeon, House Officer, Hull Royal Infirmary; Michael Ferriter, Senior Research Fellow, Rampton Hospital.

\section{References}

1 Department of Health. Carers at the Heart of 21st-Century Families and Communities: A Caring System on Your Side, A Life of Your Own. Department of Health, 2008.

2 Royal College of Psychiatrists. Forensic Psychiatric Services (leaflet). Royal College of Psychiatrists, 2005 (http://www.rcpsych.ac.uk/PDF/ ForensicPsychiatric.pdf).

3 Rampton Hospital Authority. The Forensic Directory: National Health and Private Forensic Psychiatric Facilities in the United Kingdom. Social Work Department, Rampton Hospital, 1999.

4 Department of Health. National Service Framework for Mental Health: Modern Standards and Service Models. Department of Health, 1999.

5 Department of Health. Refocusing the Care Programme Approach: Policy and Positive Practice Guidance. Department of Health, 2008. 